RESEARCH BRIEF

\title{
Aspirin for Prevention of Cardiovascular Disease
}

Vincent L. Mendy, DrPH, MPH, $\mathrm{CPH}^{1}$; Rodolfo Vargas, $\mathrm{MS}^{1}$; Lei Zhang, PhD, MBA ${ }^{1}$

Suggested citation for this article: Mendy VL, Vargas R, Zhang L. Aspirin for Prevention of Cardiovascular Disease. Prev Chronic Dis 2017;14:170171. DOI: https://doi.org/10.5888/pcd14.170171.

\section{PEER REVIEWED}

\section{Abstract}

We used data from the 2013 Mississippi Behavioral Risk Factor Surveillance System to examine aspirin use for the prevention of primary and secondary cardiovascular disease (CVD), based on the 2009 US Preventive Services Task Force (USPSTF) guidelines, among Mississippi men (aged 45-79 y) and women (aged 55-79 y) and to explore differences in aspirin use by sociodemographic characteristics. Among those without CVD, $39.1 \%$ of men and $45.9 \%$ of women reported taking aspirin, and among those with CVD, $85.9 \%$ of men and $85.1 \%$ of women reported taking aspirin. Data on preventive use of aspirin by sociodemographic characteristics yielded mixed results.

\section{Objective}

Cardiovascular disease (CVD) is the leading cause of death in Mississippi; in 2013 the state's CVD death rate was 1.4 times the national rate (1). The benefits of aspirin use in CVD prevention have been documented (2-4). The Mississippi State Department of Health (MSDH) and the Centers for Disease Control and Prevention (CDC), through a cooperative agreement (Mississippi Delta Health Collaborative), are implementing interventions across the 18-county Mississippi Delta region. These interventions target the ABCS (aspirin for those eligible, blood pressure control, cholesterol management, and smoking cessation) of heart disease and stroke prevention. However, the prevalence of aspirin use among eligible Mississippians for primary and secondary CVD prevention as recommended by the US Preventive Services Task Force (USPSTF) (5) has not been assessed.

\section{Methods}

The Behavioral Risk Factor Surveillance System (BRFSS) is a state-based, random-digit-dialed telephone survey of the noninstitutionalized US civilian population aged 18 years or older. BRFSS is conducted in all 50 states, the District of Columbia, and 3 US territories (Puerto Rico, Guam, and the US Virgin Islands) and has been approved by the human research review board at each state's department of health. Detailed information about BRFSS is available (www.cdc.gov/brfss/). Our analyses were restricted to men aged 45 to 79 years and women aged 55 to 79 years who responded to the 2013 Mississippi BRFSS. Guidelines for aspirin use were based on the 2009 USPSTF recommendations (5), not the recommendations issued in 2016 (6), because the 2009 recommendations were current when data were collected in 2013 . We excluded respondents who self-reported a contraindication to aspirin use $(\mathrm{n}=689)$ - those who responded to the question "Do you have a problem or health condition that makes taking aspirin unsafe for you?" with either "yes, not stomach related" or "yes, stomach problems" (7). Men aged 45 to 79 and women aged 55 to 79 without CVD or with contraindications to aspirin use were considered eligible to use aspirin for the primary prevention of CVD, and women and men in the same age categories with a history of CVD but without contraindications were considered eligible for aspirin use for secondary prevention.

\section{Cardiovascular disease}

CVD was defined as a yes response to at least one of the following questions: "Has a doctor, nurse, or other health professional ever told you that you had any of the following? 1) a heart attack, also called a myocardial infarction, 2) angina or coronary heart disease, 3) a stroke." Respondents who had never been told they had CVD were considered eligible for primary prevention, whereas those with a history of CVD were considered eligible for secondary prevention. Analyses were restricted to respondents who self-identified as black or white; these 2 racial groups accounted for $96.6 \%$ of the study population. This study was deemed exempt from approval by the MSDH institutional review board. Weighted prevalence and $95 \%$ confidence intervals (CIs) were calculated, 
and the $\chi^{2}$ test was used to examine sociodemographic differences. SAS version 9.4 (SAS Institute Inc) was used to perform all statistical analyses; $P$ values of less than .05 were considered significant.

\section{Results}

More than two-thirds $(68.0 \% ; 95 \%$ CI, $65.2 \%-71.2 \%)$ of eligible adults were white. Most had health insurance, more than a third were obese (body mass index $\left.\left[\mathrm{kg} / \mathrm{m}^{2}\right] \geq 30.0\right)$, and $18.9 \%(95 \% \mathrm{CI}$, $16.3 \%-21.4 \%$ ) of men and $17.8 \%$ (95\% CI, 15.4\%-20.2\%) of women reported having CVD. Among those without CVD, 39.1\% $(95 \% \mathrm{CI}, 35.4 \%-42.9 \%)$ of men and $45.9 \%(95 \% \mathrm{CI}$, $42.3 \%-49.4 \%$ ) of women were taking aspirin for primary prevention.

The prevalence of aspirin use for primary prevention among men was significantly higher among those with health insurance $(41.2 \% ; 95 \% \mathrm{CI}, 37.1 \%-45.4 \% ; P=.02)$, those with diabetes $(56.0 \% ; 95 \% \mathrm{CI}, 46.4 \%-65.6 \% ; P=.002)$, and those in poor or fair health $(47.5 \% ; 95 \mathrm{CI}, 39.0 \%-56.0 \% ; P=0.03)$ relative to their counterparts. We found significant differences by education levels $(P=.02)$ for men. For women, the prevalence of aspirin use for primary prevention was significantly higher among those in fair or poor health $(56.5 \% ; 95 \% \mathrm{CI}, 49.4 \%-63.6 \% ; P=.003)$ and those with diabetes $(60.6 \% ; 95 \% \mathrm{CI}, 53.0 \%-68.2 \% ; P<.001)$ than among their counterparts. We found significant differences among women by income level $(P=.02)$ (Table 1$)$.

Overall, of those with CVD, 85.9\% (95\% CI, 80.8\%-91.0\%) of men and $85.1 \%(95 \% \mathrm{CI}, 79.8 \%-90.5 \%)$ of women were taking aspirin. Among men with CVD, the prevalence of aspirin use was significantly higher among white men $(90.2 \% ; 95 \% \mathrm{CI}$, $85.8 \%-94.6 \%)$ than among black men (76.0\%; 95\% CI, $63.1 \%-89.0 \%)(P=.01)$. Among women with CVD, aspirin use was significantly higher among those with diabetes $(94.4 \%$; $95 \%$ CI $89.4 \%-99.4 \% ; P=.004)$ than among those without diabetes. We found significant differences by education level among women $(P=.04)$ (Table 2).

\section{Discussion}

In 2013, more than a third of eligible Mississippians without CVD were taking aspirin daily for primary prevention, while most (over $85 \%$ ) of those with CVD were taking aspirin daily. This finding is consistent with results reported for other states (8). In addition, the overall high rate of aspirin use for secondary prevention among eligible Mississippi adults is similar to results reported for nationally representative samples (9). The ongoing collaborative efforts of MSDH and CDC to promote the ABCS of heart disease prevention in the Mississippi Delta region, which has a disproportion- ately high burden of CVD, must seek to increase the awareness and promotion of strategies that target those with less education, without health insurance, and without diabetes and those with good or excellent health who are eligible for primary prevention. Evidence-based practice and clinical management procedures following CVD events, aspirin-use counseling, and community-based interventions to promote the benefits of regular aspirin use among those eligible are needed to increase aspirin use (9), particularly among black adults with CVD. Future studies should further examine the disparities in aspirin use among eligible Mississippi adults.

These findings have potential limitations. First, the data are selfreported, which could lead to recall bias (9), and aspirin does not require a prescription for purchase. Second, because of the crosssectional study design there could be temporality bias. Third, the questions used in BRFSS to define CVD might underestimate CVD in the population, because they do not refer to all types of CVD. Increased aspirin use could improve CVD risk prevention and reduction among eligible Mississippi adults. Our findings indicate that a significant proportion of eligible Mississippi adults could benefit from using aspirin to prevent CVD (6).

\section{Acknowledgments}

We thank Cassandra Dove, Dr Victor Sutton, and Dr Mary Currier of MSDH and Dr Fleetwood Loustalot of the Division for Heart Disease and Stroke Prevention, CDC. Research reported in this article was supported by CDC grant no. 5U50DP003088-04.

\section{Author Information}

Corresponding Author: Vincent L. Mendy, DrPH, MPH, CPH, Office of Health Data and Research, Mississippi State Department of Health, 570 East Woodrow Wilson Drive, Jackson, MS 39215. Telephone: 601-576-8165. Email: vincent.mendy@msdh.ms.gov.

Author Affiliations: ${ }^{1}$ Office of Health Data and Research, Mississippi State Department of Health, Jackson, Mississippi.

\section{References}

1. Centers for Disease Control and Prevention, National Center for Health Statistics. Underlying cause of death 1999-2015 on CDC WONDER online database, released December, 2016. Data are from the Multiple Cause of Death Files, 1999-2015, as compiled from data provided by the 57 vital statistics jurisdictions through the Vital Statistics Cooperative Program. http://wonder.cdc.gov/ucd-icd10.html. Accessed January 8, 2017.

\footnotetext{
The opinions expressed by authors contributing to this journal do not necessarily reflect the opinions of the U.S. Department of Health and Human Services, the Public Health Service, the Centers for Disease Control and Prevention, or the authors' affiliated institutions.
} 
2. Antithrombotic Trialists' (ATT) Collaboration; Baigent C, Blackwell L, Collins R, Emberson J, Godwin J, Peto R, et al.. Aspirin in the primary and secondary prevention of vascular disease: collaborative meta-analysis of individual participant data from randomised trials. Lancet 2009;373(9678):1849-60.

3. Berger JS, Lala A, Krantz MJ, Baker GS, Hiatt WR. Aspirin for the prevention of cardiovascular events in patients without clinical cardiovascular disease: a meta-analysis of randomized trials. Am Heart J 2011;162(1):115-24.e2.

4. Raju N, Sobieraj-Teague M, Hirsh J, O’Donnell M, Eikelboom $\mathrm{J}$. Effect of aspirin on mortality in the primary prevention of cardiovascular disease. Am J Med 2011;124(7):621-9.

5. US Preventive Services Task Force. Aspirin for the prevention of cardiovascular disease: US Preventive Services Task Force recommendation statement. Ann Intern Med 2009; 150(6):396-404.

6. Bibbins-Domingo K; US Preventive Services Task Force. Aspirin use for the primary prevention of cardiovascular disease and colorectal cancer: US Preventive Services Task Force recommendation statement. Ann Intern Med 2016; 164(12):836-45.

7. Tchwenko S, Fleming E, Perry GS. Aspirin use for the primary prevention of myocardial infarction among men in North Carolina, 2013. Prev Chronic Dis 2015;12:E202.

8. Ajani UA, Ford ES, Greenland KJ, Giles WH, Mokdad AH. Aspirin use among US adults: Behavioral Risk Factor Surveillance System. Am J Prev Med 2006;30(1):74-7.

9. Fang J, George MG, Hong Y, Loustalot F. Use of aspirin for prevention of recurrent atherosclerotic cardiovascular disease among adults - 20 states and the District of Columbia, 2013. MMWR Morb Mortal Wkly Rep 2015;64(27):733-7.

The opinions expressed by authors contributing to this journal do not necessarily reflect the opinions of the U.S. Department of Health and Human Services, the Public Health Service, the Centers for Disease Control and Prevention, or the authors' affiliated institutions. 


\section{Tables}

Table 1. Characteristics of Eligible Mississippi Adults ${ }^{\mathrm{a}}$ Taking Aspirin for the Primary Prevention of Cardiovascular Disease, Mississippi Behavioral Risk Factor Surveillance System, 2013

\begin{tabular}{|c|c|c|c|c|c|c|}
\hline \multirow[b]{2}{*}{ Characteristic } & \multicolumn{3}{|c|}{ Men Aged 45-79 Years } & \multicolumn{3}{|c|}{ Women Aged 55-79 Years } \\
\hline & Weighted Frequency & Weighted \% (95\% Cl) & $P$ Value $^{\mathrm{b}}$ & Weighted Frequency & Weighted \% (95\% Cl) & $P$ Value $^{b}$ \\
\hline Overall & 133,052 & $39.1(35.4-42.9)$ & & 107,814 & $45.9(42.3-49.4)$ & \\
\hline \multicolumn{7}{|l|}{ Race } \\
\hline Black & 36,082 & $34.0(27.0-41.1)$ & \multirow{2}{*}{.08} & 35,237 & $48.5(42.1-55.0)$ & \multirow{2}{*}{.35} \\
\hline White & 96,770 & $41.7(37.3-46.1)$ & & 72,421 & $44.8(40.6-49.1)$ & \\
\hline \multicolumn{7}{|l|}{ Education } \\
\hline$<$ High school diploma & 23,225 & $30.4(21.8-39.0)$ & \multirow{3}{*}{.02} & 24,285 & $47.0(37.4-56.6)$ & \multirow{3}{*}{.31} \\
\hline $\begin{array}{l}\text { High school diploma } \\
\text { or equivalent }\end{array}$ & 41,391 & $37.6(31.3-43.9)$ & & 39,079 & $49.2(43.2-55.2)$ & \\
\hline >High school diploma & 68,435 & $44.7(39.4-50.1)$ & & 44,157 & $42.6(38.0-47.2)$ & \\
\hline \multicolumn{7}{|c|}{ Annual household income, $\$$} \\
\hline$<35,000$ & 58,244 & $41.2(35.1-47.3)$ & \multirow{3}{*}{.57} & 54,993 & $48.8(43.3-54.3)$ & \multirow{3}{*}{.02} \\
\hline$\geq 35,000$ & 64,604 & $38.2(33.0-43.4)$ & & 33,243 & 39.5 (34.1-45.0) & \\
\hline No answer & 10,204 & $34.6(22.6-46.5)$ & & 19,638 & $51.1(43.4-58.7)$ & \\
\hline \multicolumn{7}{|l|}{ Health insurance } \\
\hline Yes & 115,576 & $41.2(37.1-45.4)$ & \multirow{2}{*}{.02} & 95,911 & $47.6(44.0-51.2)$ & \multirow{2}{*}{.07} \\
\hline No & 17,441 & $29.5(20.8-38.1)$ & & 11,791 & $35.5(23.5-47.5)$ & \\
\hline \multicolumn{7}{|l|}{ General health } \\
\hline Fair/poor & 34,164 & $47.5(39.0-56.0)$ & \multirow{2}{*}{.03} & 37,690 & $56.5(49.4-63.6)$ & \multirow{2}{*}{.001} \\
\hline Excellent/good & 98,888 & $36.9(32.7-41.1)$ & & 70,038 & $41.8(37.9-45.7)$ & \\
\hline \multicolumn{7}{|l|}{ Current smoking } \\
\hline Yes & 29,336 & $36.0(27.9-44.2)$ & \multirow{2}{*}{.37} & 16,809 & $43.8(33.6-54.0)$ & \multirow{2}{*}{.66} \\
\hline No & 103,337 & $40.3(36.1-44.6)$ & & 90,155 & $46.2(42.5-50.0)$ & \\
\hline \multicolumn{7}{|l|}{ Body mass index, $\mathrm{kg} / \mathrm{m}^{2}$} \\
\hline$<25.0$ & 21,686 & $31.9(24.2-39.6)$ & \multirow{3}{*}{.12} & 30,108 & $45.7(38.7-52.7)$ & \multirow{3}{*}{.27} \\
\hline 25.0 to $<30.0$ & 56,059 & $40.5(34.6-46.4)$ & & 33,879 & $43.3(37.1-49.5)$ & \\
\hline$\geq 30.0$ & 53,892 & $40.5(34.6-46.4)$ & & 37,453 & $50.4(44.5-56.2)$ & \\
\hline \multicolumn{7}{|l|}{ Diabetes } \\
\hline Yes & 29,225 & $56.0(46.4-65.6)$ & \multirow{2}{*}{.001} & 27,838 & $60.6(53.0-68.2)$ & \multirow{2}{*}{$<.001$} \\
\hline No & 103,827 & $36.1(32.0-40.2)$ & & 79,977 & $42.3(38.3-46.3)$ & \\
\hline
\end{tabular}

Abbreviation: $\mathrm{Cl}$, confidence interval.

${ }^{a}$ Respondents who had never been told by a physician or health care provider that they had a stroke, heart attack, or coronary heart disease.

${ }^{b}$ Determined by using $x^{2}$ test.

The opinions expressed by authors contributing to this journal do not necessarily reflect the opinions of the U.S. Department of Health and Human Services, the Public Health Service, the Centers for Disease Control and Prevention, or the authors' affiliated institutions. 
Table 2. Eligible Mississippi Adults ${ }^{a}$ Taking Aspirin for the Secondary Prevention of Cardiovascular Disease, Mississippi Behavioral Risk Factor Surveillance System, 2013

\begin{tabular}{|c|c|c|c|c|c|c|}
\hline \multirow[b]{2}{*}{ Characteristic } & \multicolumn{3}{|c|}{ Men Aged 45-79 Years } & \multicolumn{3}{|c|}{ Women Aged 55-79 Years } \\
\hline & $\begin{array}{l}\text { Weighted } \\
\text { Frequency }\end{array}$ & Weighted \% (95\% Cl) & $P$ Value $^{\mathrm{b}}$ & $\begin{array}{l}\text { Weighted } \\
\text { Frequency }\end{array}$ & Weighted \% (95\% Cl) & $P$ Value $^{\mathrm{b}}$ \\
\hline Overall & 68,563 & $85.9(80.8-91.0)$ & & 43,100 & $85.1(79.8-90.5)$ & \\
\hline \multicolumn{7}{|l|}{ Race } \\
\hline Black & 18,096 & $76.0(63.1-89.0)$ & \multirow{2}{*}{.01} & 13,392 & $81.4(72.3-90.5)$ & \multirow{2}{*}{.36} \\
\hline White & 50,331 & $90.2(85.8-94.6)$ & & 28,911 & $86.6(79.8-93.4)$ & \\
\hline \multicolumn{7}{|l|}{ Education } \\
\hline$<$ High school diploma & 22,776 & $86.4(76.9-95.9)$ & \multirow{3}{*}{.79} & 12,223 & $76.2(63.0-89.3)$ & \multirow{3}{*}{.04} \\
\hline High school diploma or equivalent & 20,579 & $88.0(79.9-96.2)$ & & 15,597 & $88.6(82.6-94.6)$ & \\
\hline >High school diploma & 25,208 & $83.8(75.4-92.2)$ & & 14,972 & $89.8(83.2-96.5)$ & \\
\hline \multicolumn{7}{|l|}{ Annual household income, $\$$} \\
\hline$<35,000$ & 40,150 & $85.4(78.5-92.5)$ & \multirow{3}{*}{.50} & 25,319 & $81.6(73.9-89.2)$ & \multirow{3}{*}{.13} \\
\hline$\geq 35,000$ & 22,712 & $89.0(81.8-96.2)$ & & 6,081 & $86.9(73.5-100.0)$ & \\
\hline No answer & 5,701 & $78.0(58.1-97.8)$ & & 11,700 & $92.9(87.3-98.5)$ & \\
\hline \multicolumn{7}{|l|}{ Health insurance } \\
\hline Yes & 64,666 & $85.9(80.7-91.1)$ & \multirow{2}{*}{.94} & 39,134 & $85.4(79.8-91.0)$ & \multirow{2}{*}{.72} \\
\hline No & 3,830 & $85.1(62.8-100.0)$ & & 3,792 & $82.0(62.7-100.0)$ & \\
\hline \multicolumn{7}{|l|}{ General health } \\
\hline Fair/poor & 39,474 & $86.5(79.7-93.2)$ & \multirow{2}{*}{.96} & 24,993 & $84.7(77.7-91.6)$ & \multirow{2}{*}{.85} \\
\hline Excellent/good & 28,653 & $86.7(79.3-94.2)$ & & 18,107 & $85.8(77.4-94.1)$ & \\
\hline \multicolumn{7}{|l|}{ Current smoking } \\
\hline Yes & 18,993 & $82.9(72.0-93.9)$ & \multirow{2}{*}{.49} & 8,398 & $76.8(61.2-92.3)$ & \multirow{2}{*}{.13} \\
\hline No & 49,569 & $87.1(81.5-92.7)$ & & 34,408 & $87.3(82.2-92.5)$ & \\
\hline \multicolumn{7}{|l|}{ Body mass index, $\mathrm{kg} / \mathrm{m}^{2}$} \\
\hline$<25.0$ & 12,660 & $82.8(71.0-94.6)$ & \multirow{3}{*}{.16} & 10,634 & $88.3(81.0-95.7)$ & \multirow{3}{*}{.40} \\
\hline 25.0 to $<30.0$ & 27,070 & $93.2(87.8-98.6)$ & & 13,946 & $87.1(77.4-96.7)$ & \\
\hline$\geq 30.0$ & 26,920 & $85.0(77.3-92.7)$ & & 15,791 & $80.2(70.2-90.2)$ & \\
\hline \multicolumn{7}{|l|}{ Diabetes } \\
\hline Yes & 27,073 & $89.0(81.9-96.0)$ & \multirow{2}{*}{.33} & 17,976 & $94.4(89.4-99.4)$ & \multirow{2}{*}{.004} \\
\hline No & 41,489 & $84.0(77.1-90.8)$ & & 24,992 & $79.4(71.6-87.3)$ & \\
\hline
\end{tabular}

Abbreviation: $\mathrm{Cl}$, confidence interval.

${ }^{a}$ Respondents who reported that a doctor or health care provider had previously told them that they had been diagnosed with a stroke, heart attack, or coronary heart disease.

${ }^{b}$ Determined by using $x^{2}$ test.

The opinions expressed by authors contributing to this journal do not necessarily reflect the opinions of the U.S. Department of Health and Human Services, the Public Health Service, the Centers for Disease Control and Prevention, or the authors' affiliated institutions. 